\title{
Can Machine Translation meet the needs of official language minority communities in Canada? A recipient evaluation
}

\author{
Lynne Bowker \\ University of Ottawa
}

Canada is an officially bilingual country, but the only legal requirement is for federal services to be offered in both official languages. Therefore, services provided by provincial and municipal governments are typically offered only in the language of the majority, with cost being cited as the main obstacle to providing translation. This paper presents a recipient evaluation designed to determine whether machine translation could be used as a cost-effective means of increasing translation services in Canadian official language minority communities. The results show that not all communities have the same needs, and that raw or rapidly post-edited MT output is more suitable for information assimilation, while maximally post-edited MT output is a minimum requirement when translation is intended as a means of cultural preservation and promotion. The survey also suggests that average recipients are more receptive to MT than are language professionals.

\section{Introduction}

Evaluation of machine translation (MT) can and must take many forms depending both on the goal of the evaluation and on which stakeholders are involved (White, 2003). Common types of evaluations include developer evaluations, researcher evaluations and end-user evaluations (Dorr et al., 1999, pp. 48-54). However, Chesterman and Wagner (2002, pp. 80-84) describe another way of approaching MT evaluation, noting that it is possible to view translation as a service, intangible but wholly dependent on customer satisfaction; therefore, to measure translation quality, one needs to measure customer satisfaction. Such an approach to evaluating MT is referred to as a recipient evaluation, which is described by Trujillo (1999, p. 255) as an evaluation performed by the recipients of the translation in order to evaluate quality, cost and speed. According to Loffler-Laurian (1996, p. 69), the recipients of MT output are in the best position to judge whether this output satisfies their requirements.

Although the literature on MT evaluation is extensive, comparatively little attention is paid to recipient evaluations. While it is likely that many organizations that employ MT conduct some type of recipient evaluation, the details of these evaluations are not widely published. A literature survey presents several indirect references to recipient evaluations (e.g. Nuutila, 1996; Senez, 1998; Brace, 2000), but for many of these, little specific in- 
formation about the evaluation procedure is provided, and the sparse information that is available is largely anecdotal in nature. Notable exceptions are Henisz-Dostert et al. (1979) and Vasconcellos and Bostad (1992) who furnish more detailed reports on recipient evaluations. Although these reports are valuable, they have become somewhat dated given the pace at which MT technology is both improving and taking hold.

Despite the shortage of references to recipient evaluations, there is no doubt that there are many recipients of MT output. In this era of globalization, increased demand for translation has been coupled not only with shorter deadlines but also with a shortage of human translators available to meet this demand (ABI, 2002; Shadbolt, 2002, pp. 30-31). One way to ease the burden has been to make greater use of MT systems for certain types of translation tasks. MT systems can produce translations far more quickly, and often more cheaply, than human translators; however, in the vast majority of cases, the quality of raw MT output is inferior to that produced by human translators.

Nevertheless, there are documented cases when MT fills a genuine need, such as automatic translation of product knowledge bases carried out in order to reduce the number of technical support calls to companies such as Intel and Microsoft (Dillinger \& Gerber, 2009). Moreover, a growing body of evidence demonstrates that use of MT is rising. For example, the Allied Business Intelligence (ABI) report of 2002 identified MT as an area with "exponential growth potential" (ABI 2002: 5.21) and predicted that by 2007 the global translation market would be worth US\$11.5 billion and the MT market worth US\$133.8 million (ABI, 2002, 5.23). According to Brace (2000, p. 220), use of MT at the European Commission has soared since the early 1990s: In 1996, 220,000 pages were run through the MT system; and by 2000 this number had more than doubled to 546,000 pages (ABI, 2002:, p. 5.14). A more recent account (DePalma, 2007, p. 46) notes that the city of San Francisco has experimented with MT to provide translations in various languages to residents who have limited English proficiency. The following caveat appears on the city's Web site: "We prefer to provide automated translation rather than no translation at all in order at least to provide speakers of other languages an overall sense of the information available on a web page."

The experiment in San Francisco raises an important point, one underscored by Somers (2003, p. 88) in a paper on translation technologies and minority languages: Speakers of non-indigenous minority languages are typically not well served in their local communities. In the case outlined by DePalma (2007), MT is offered as a sort of 'bonus' for residents with limited English. In other words, the city of San Francisco is not obliged to translate texts, but offers the service as a sort of goodwill gesture. Many other municipalities are considerably less generous in attempting to meet the needs of linguistic minorities.

This difficulty of accessing information in one's own language can be witnessed even in countries such as Canada that officially mandate bi- 
lingualism, In Canada, MT does not seem to be heavily used as a means of providing access to text in both official languages. ${ }^{1}$ This could be because MT is generally associated with lower quality results as compared to human translation; so offering MT as a solution for translating an official language may be perceived as an indication that one of the languages is somehow "less official" or of lower status than the other and therefore does not deserve high quality translation. To the best of our knowledge, no serious investigation has been conducted into the reception of MT in a context where bilingualism is officially legislated. Would the use of MT be rejected outright for reasons of perceived loss of status or equality? Or would the case of "having an automated translation is better than having no translation at all" apply as it did in the San Francisco experiment described by DePalma (2007, p. 46)? Would speakers of the two official language groups react to MT in the same way? The goal of this paper is to move towards filling this knowledge gap by reporting on a large-scale recipient evaluation that specifically targets members of Canada's official language minority communities (OLMCs).

The paper begins with an overview of what it means to be an OLMC in Canada, introducing two different communities as examples: a Frenchspeaking OLMC in Saskatchewan, and an English-speaking OLMC in West Quebec. Next, the costs of providing translation services to OLMCs are considered, followed by description of an experiment that investigates whether MT could be used as a means of partially meeting the translation needs of these OLMCs. The experiment takes the form of parallel recipient evaluations conducted in the Saskatchewan and West Quebec OLMCs, and the results of these evaluations are discussed and compared.

\section{Official bilingualism and official language minority communities (OLMCs) in Canada}

Canada is a country with two official languages: English and French. The French language is used predominantly in the province of Quebec, while English is more prevalent elsewhere in the country. In Canada, OLMC designation therefore refers to an English-speaking community within Quebec or a French-speaking community outside Quebec.

There is sometimes confusion about precisely what it means to be an officially bilingual country. In the case of Canada, English and French became recognized as the official languages of all federal institutions in the country following passage of the Official Languages Act in 1969. In 1988, a new Official Languages Act came into force, which sets the following three basic objectives of the Government of Canada: 
- $\quad$ To ensure respect for English and French as the official languages of Canada and ensure equality of status and equal rights and privileges as to their use in all federal institutions;

- $\quad$ To set out the powers, duties and functions of federal institutions with respect to the official languages of Canada;

- To support the development of English and French linguistic minority communities and generally advance the equality of status and use of the English and French languages within Canadian society.

In November 2005 the Parliament of Canada passed additional amendments to the Official Languages Act, which now requires all federal government agencies to adopt measures to foster growth and development of OLMCs.

For the most part, the federal government has done a reasonable job of meeting the first two objectives. Canadians generally have access to information about federal services in both languages, and they can usually interact with federal institutions in the official language of their choice. However, Canada is divided into ten provinces and three territories, with the result that the Canadian federal structure of government is extremely decentralized. Although this decentralization affords flexibility, in the case of official languages it also brings complexity. Provincial governments have broad responsibilities and they vigorously defend their almost exclusive jurisdiction over important areas that, in other countries, would be strongly influenced or controlled by central national authorities. For example, in Canada, healthcare, education, social welfare, and civil rights all fall under provincial rather than federal jurisdiction.

Although the federal government can encourage development and equal treatment of OLMCs in the 13 provinces and territories, 12 of these are not legally required to provide provincial or territorial services in both official languages. ${ }^{2}$ The same is true of the vast majority of municipal governments. As a result, provincial and municipal services are generally offered only in the language of the majority. Understandably, this approach does not sit well with members of the OLMCs. In a cross-Canada consultation exercise conducted by the Office of the Commissioner of Official Languages (OCOL), members of such communities were severe in their judgments of the behaviour of provincial governments with respect to the official languages of Canada (Adam, 2000, p. 5). The OCOL went on to criticize the situation, noting that "all too often, the federal government transfers its responsibilities to other levels of government, or to the private sector, without ensuring continued respect for the language rights of the persons receiving these services" (Adam, 2001, p. 39). These observations have since been echoed by the Standing Joint Committee on Official Languages in a report to the Parliament of Canada (SJCOL, 2002, p. 2) and by Lord (2008, pp. 16-17) in the Report on the Government of Canada's Consultations on Linguistic Duality and Official Languages.

Given this situation, we set out to conduct a preliminary investigation into whether MT could offer at least a partial solution for addressing 
the unmet translation needs of Canadians living in OLMCs. A recipient evaluation is highly appropriate in this case because in order for use of MT to be considered viable, the intended recipients of the target texts must accept the output produced by MT systems. We selected two different communities for this parallel study of the reception of MT output in French and English OLMCs: the Fransaskois and West Quebecers. The following sections introduce these two OLMCs and describe the respective contexts in which they have evolved. By gaining deeper understanding of some of the challenges facing these OLMCs, we can better interpret their reactions to MT output.

\subsection{The Fransaskois}

The first of the two OLMCs studied is the Fransaskois ${ }^{3}$, a community of Francophones living in the predominantly English-speaking province of Saskatchewan, located in the midwest of Canada. Data from Statistics Canada's 2006 census show that the province of Saskatchewan has a total population of 968,157, with approximately 19,500 inhabitants (roughly $2 \%$ of the total population) having French as a native language. This figure has declined from 1951, when approximately $4.4 \%$ of the residents of Saskatchewan were Francophones (OCOL, 2007, p. 22).

Historically, Francophones settled in small rural pockets across Saskatchewan, and according to the OCOL (2007, p. 15), statistics indicate that the majority of Fransaskois still reside in predominantly rural areas. As Churchill (1998, p. 68) notes, rurally located OLMCs such as the Fransaskois face particular challenges. They are threatened by assimilation, especially if existing levels of federal and/or provincial support for community organizations are reduced. Moreover, provincial governments have proved themselves largely reticent when it comes to adopting measures to assist development of OLMCs. Churchill (1998, p. 40) also notes that in provinces like Saskatchewan, which have an English-speaking majority and are primarily rural, the expansion of public services in French has been driven primarily by legal and constitutional pressures rather than by provincial politicians seeking to improve the status of the French language. Francophone residents of Saskatchewan who participated in the OCOL's crossCanada consultations in 2000 were very clear that this lack of political support is keenly felt in their province (Adam, 2000, p. 114).

Furthermore, it would seem that members of the Fransaskois community are also facing an uphill struggle to gain recognition and support outside the political arena. Several investigations and surveys have revealed that Anglophones living in Saskatchewan do not find the French community to be prominent and have less interest in participating in bilingual education than do Anglophones from other provinces (OCOL, 2007, p. 4-13). The Fransaskois community thus faces a considerable challenge in raising its visibility and promoting the value of its language and culture to the Anglophone majority living in Saskatchewan. 
Another issue that may be perceived as a factor diminishing the importance of French in Saskatchewan is the significant presence of Aboriginal or First Nations language use in the province. Similarly, as increasing numbers of immigrants from various countries come to live in Canada, members of many OLMCs, including the Fransaskois, have concerns about the long-term effects of the country's rapidly changing demographic composition. The situation in the province of Saskatchewan is particularly striking: While approximately $2 \%$ of the population is Francophone, over $12 \%$ report that their mother tongue is something other than one of Canada's two official languages. As noted by Lesage et al. (2008, p. 37), many members of OLMCs are concerned that their status as founding peoples will diminish if their numbers decline in relation to those of other cultures, and that protection granted under the Official Languages Act could be diluted by special measures to promote cultural diversity. Although multiculturalism policies and the Act are not incompatible, members of OLMCs "increasingly feel like a link in the cultural diversity chain and, as a result, fear losing whatever gains they have achieved under the Act" (Lesage et al., 2008, p. 37).

\subsection{West Quebecers}

The second OLMC studied is the community of West Quebec ${ }^{4}$. This community consists of English-speakers who live in the Outaouais region, the southwestern region of the predominantly French-speaking province of Quebec. Data from Statistics Canada's 2006 census show that the Outaouais region has a total population of 281,650 , with approximately 35,815 inhabitants (roughly 12.7\%) having English as a native language. However, according to both Jedwab and Maynard (2008, p. 167) and the Quebec Community Groups Network (QCGN, 2004, p. 8), the English-speaking community of Quebec requires a broader definition than simply "native speaker". According to the QCGN (2004, p. 8), "The English-speaking community of Quebec is made up of multiple communities that are diverse, multicultural and multiracial. These communities include citizens throughout Quebec who choose to use the English language and who identify with the English-speaking community".

The QCGN goes on to note that, according to this broader definition, the total number of English speakers in West Quebec in 2001 was approximately 53,948 . This means that in addition to the $12.7 \%$ of the Outaouais region's inhabitants who claim to be native English-speakers, another $6.4 \%$ of the region's total population use English as their preferred official language. Therefore, the region's total percentage of English speakers is $19.1 \%$, of whom approximately one-third are non-native speakers. It is notable that this inclusiveness within the English-language community seems to differ somewhat from the attitude in French-speaking OLMCs, where, as discussed earlier, speakers of other languages are sometimes viewed as competing with the OLMCs in the context of multiculturalism policies. 
If multiculturalism is seen as less of a threat in the English-speaking OLMCs, one issue of great concern is that the population of Englishspeakers is both declining and aging. This situation has arisen largely as a result of language laws introduced in the province of Quebec. Bill 101 (the Charter of the French Language), for example, had the objective of ensuring that French-speaking Quebecers had the right to receive services in French, not only in the narrow domain of provincial and municipal services but also in all sectors of industry, commerce and the professions. For the French-speaking majority, the objective was to protect the French language; for the English-speaking minority, it appeared that the primary de facto objective was to reduce the visibility, utilization and attractiveness of the English language. One of the most serious effects of the introduction of Bill 101 has been the demographic impact on Quebec's non-Francophone population. In this province, Bill 101 has become a source of irritation and frustration for much of the English-speaking minority, which has suffered. This has contributed to drastic decline in the English-speaking population, especially the youth population, due to out-migration (NHRDCELM, 2000, p. 11; QCGN, 2004, p. 5). Moreover, as Churchill (1998, p. 37) reports, the traditional in-migration flow of English-speakers to Quebec from other provinces has simultaneously been seriously reduced, largely in reaction to Bill 101.

Interestingly, Churchill (1998, p. 47) observes that Quebec's language laws have also produced a more positive consequence: Among the young English-speakers who remain in the province, there appears to be consensus that French has a pre-eminent place in all aspects of life in Quebec, and that being a Quebec English-speaker in the future implies the practical necessity of being bilingual in French. This observation is echoed by Jedwab and Maynard (2008, p; 168), who credit dramatic rise in bilingualism in OLMCs in Quebec (from 37\% in 1971 to 69\% in 2006) to the determination of those in the English-speaking community who have chosen to remain in the province.

The National Human Resources Development Committee for the English Linguistic Minority (NHRDCELM, 2000, p. 17) reports that another challenge facing West Quebecers is the serious need in the OLMCs of Quebec for development and maintenance of services, such as business development, health and social services, in the English language. As Jedwab and Maynard (2008, p. 175) report, the majority (64.2\%) of Englishspeakers living in Quebec are very satisfied with access to English services offered by the federal government, but only $24 \%$ are very satisfied with the English-language services provided by the Quebec provincial government, which include healthcare and social services. Likwise, only 17\% of Quebec's English-speakers felt that English-language services provided by the Quebec government had improved in the previous five years.

In a related vein, because the English language is extremely strong at the global level, there often arises a false impression that English-speaking communities in Quebec have a healthy vitality. However, as several exam- 
ples demonstrate, this perception obscures the actual situation at the level of community vitality. For example, there are no English-language hospitals in the province of Quebec, although research has shown that being unable to communicate in one's own language with health professionals is a considerable barrier to accessing adequate healthcare (Pottie et al., 2008). Moreover, as both the NHRDCELM (2000, p. 49) and Jedwab and Maynard (2008, p. 168) note, in West Quebec, English-speakers do not have access to any regional English-language daily newspapers or radio coverage, and thus which means that they receive little English-language media coverage of information about what affects them most in their daily lives: decisions and events in their hometown and home province.

\section{Examining the cost of providing translation to OLMCs}

A principal reason that provincial and municipal governments within Canada are reluctant to provide bilingual documents (such as Web sites) is that translation can be both costly and time consuming (OCOL, 2005, p. 58; OCOL, 2007, p. 57). One of the recurring criticisms levelled at bilingualism in Canada since the 1960s has been its cost to taxpayers (Adam, 2005, p. 107). Churchill (1998, p. 63) emphasizes that for official languages policies to succeed, their costs must be kept to a reasonable level. Moreover, it is not simply a matter of finding a lump sum of money to pay for a one-off translation of existing Web sites. Rather, ongoing commitment is required because it is exceedingly difficult (and unpopular!) for a government to curtail a service once it has been offered, and the Web is a dynamic resource that updates constantly.

Another oft-cited reason for not translating such Web sites is that there is a recognized shortage of professional translators in Canada (Clavet, 2002, p. 13; Lord, 2008, p. 15). This is exacerbated by the fact that many of the country's current translators belong to the Baby Boom generation, who will soon be retiring (CTISC, 1999, p. 79).

Given these circumstances, the challenge of providing bilingual Web sites is becoming increasingly intractable because, as the Internet's popularity grows, the volume of documents awaiting translation also grows. As noted by the OCOL $(2005$, p. 27$)$, the advent of the Web has given rise to a $15 \%$ increase since 1996 in the volume of content to be translated. Clavet (2002, p. 13) notes that this number may be closer to $25 \%$.

As early as 1999, when the Internet was still a relatively new phenomenon, the OCOL found the lack of resources (both financial and human) a systemic obstacle blocking translation of documents to be posted to the Web. The OCOL initially suggested that larger budgets were required if the volume of documents to be translated for inclusion on the Web was to be increased (OCOL, 1999). However, the OCOL (2005, p. 58) also recognizes that institutions do not have endless supplies of financial and human 
resources for translation, and that, as a result, these institutions often face difficult choices that usually entail some form of selective translation.

Therefore, in addition to recommending budget increases where they are possible, the OCOL has repeatedly suggested that technology be explored as a partial solution to helping bridge the gap between supply and demand for translation 5 (Adam, 2001, p. 27; Adam, 2005, p. 55; Clavet, p. 2002: 52; OCOL 2005: 58-59). For example, the OCOL proposes that

the government should also explore new avenues to increase its effectiveness and efficiency in creating, managing, and translating documents. Specifically, it should substantially step up its use of technolinguistic tools and adapt its organizational policies and practices to maximize the impact of its software. (OCOL, 2005, p. 58)

This type of strategy has since been echoed by others, including Lord (2008, pp. 15-16).

In fact, the OCOL cites the Pan American Health Organization as an example of the success that can be achieved by using the output of MT software in combination with revision by professional translators:

Since 1985, the Pan American Health Organization (PAHO) has been using automatic translation software called ENGSPAN to translate most of its documents from English into Spanish. While fully aware that this technology cannot produce perfect results on its own, PAHO management has put in place a process whereby ENGSPAN supports the work of translators rather than eliminates it: the document to be translated is first subject to an automatic correction and/or human revision; it is then translated automatically by the automatic translation software before finally being revised by a professional translator. The results of this approach are conclusive: PAHO has been able to reduce its translation costs per word by $31 \%$; most translations are delivered within specified deadlines; and most readers find the quality acceptable. (OCOL, 2005, p. 59)

However, the Government of Canada's Translation Bureau reacted negatively to this suggestion, stating that it would be unreasonable to use MT systems to translate the content of government Web sites automatically because any reduction in translation costs would inevitably come at the cost of a dramatic drop in quality (OCOL, 2005, pp. 60-61). This is in line with observations made by Guyon (2003), for example, as part of an investigation into whether MT could be a viable option for translating the Web site content of a Canadian museum. Guyon concluded that

Permanently displaying a machine translation would tarnish the prestigious image the museums enjoy because of the customary quality of their content. We recommend that the museums post appropriate 
warnings if they wish to add links to one or more machine translation engines and that they resist the temptation to use machine translation for permanent content. (Guyon, 2003, p. 173)

The need for quality is not in question. The OCOL maintains that linguistic duality reflects a major commitment that involves not only promoting the equal status of the two official languages throughout Canada, but also the quality of services offered to the public in both English and French (Adam, 2001, p. 17; OCOL, 2005, p. 32). To this end, the OCOL recommends that if an institution is to focus on providing quality service in both official languages, it should adhere to a series of guiding principles, which include, among others:

- Establishing contacts with OLMCs to determine their need for the services offered; and

- Measuring client satisfaction. (Adam, 2001, p. 76)

\section{Recipient evaluations in two OLMCs}

In summarizing the ideas outlined in the preceding sections, we can identify a number of key points. Firstly, it is clear that members of OLMCs have substantial unmet translation needs at the level of provincial (and municipal) services. It is also clear that tight budgets coupled with a shortage of professional translators present a substantial roadblock to having this material translated professionally. For this reason, the OCOL has suggested that translation technology should be investigated more fully to determine if it can be used to increase the effectiveness and efficiency of translation services for OLMCs. At the same time, however, the OCOL warns that a more cost-effective translation solution should not come at the expense of translation quality. Finally, the OCOL recommends that members of the OLMCs should be consulted to determine their needs and their level of satisfaction with proposed solutions.

With these points in mind, we set out to conduct an investigation into whether MT can provide a faster and more cost-effective means of translation that would in turn enable provincial and municipal governments and agencies to offer a wider range of translation services to OLMCs.

As noted above, MT is unquestionably faster and cheaper than human translation but, in the vast majority of cases, unedited MT output is of lesser quality than human translation. A key question to be answered is whether members of the OLMCs will accept some form (either raw or edited) of MT output. In order for MT use to be considered viable, the intended recipients of the target texts must be willing to accept the output produced by MT systems. As noted by the OCOL (Adam, 2001, p. 76), as well as by MT researchers Loffler-Laurian (1996, p. 69) and Trujillo (1999; 
p. 255), the intended recipients of the translated texts are in the best position to decide whether their needs can be suitably met by those texts. Thus, to ascertain whether members of the Fransaskois and West Quebec OLMCs would be accepting of MT, we conducted parallel recipient evaluations in order to determine the extent to which MT can help to meet some of their translation needs.

Experience has clearly shown that MT is not a viable option for all types of texts or situations (Church \& Hovy, 1993; L'Homme, 2008, p. 273). It is generally accepted that MT is better viewed as a translation aid, rather than as outright replacement of human translators. With this in mind, our investigation has two main goals; to identify the translation needs of the two OLMCs that are currently not being met; and to evaluate the potential of some form of MT for meeting those particular needs. Note that the investigations in the two OLMCs were conducted a year apart: The Fransaskois community was investigated first, followed by the West Quebec community the next year. Nevertheless, the two studies are largely parallel in nature, so the general methodology described in the following sections applies to both.

\subsection{Preparatory work}

As a first step, an initial survey was sent to members of the two OLMCs asking them to specify the types of texts currently made available to them only in the official language of the majority but which they would like to have made available in their own official language. This initial survey was sent by email to two active community associations - the Assemblée communautaire fransaskoise $(A C F)$ and the Regional Association of West Quebecers (RAWQ) - with the request that it be distributed among their members. ${ }^{6}$ Responses to this initial survey totalled 25 from the Fransaskois community and 27 from the West Quebec community.

For the Fransaskois community, suggestions received included tourism-related texts, news items of local interest, and various types of general information posted on the Web sites of the provincial and municipal governments and agencies. The third suggestion was most frequently given.

In regard to the West Quebec community, suggestions received included municipal by-laws, news items of local interest, health-related information, and information posted on the Web sites of provincial and municipal governments and agencies. The last was again the most frequently cited.

We gathered samples of these various types of texts and ran preliminary tests using three commercially available desktop MT systems ${ }^{7}$ (Power Translator Pro, Reverso Pro and Systran) to see which of these types of texts were most amenable to MT, and which system would produce the highest quality output for these texts.

Based on these initial system tests, the best candidates were the Web sites of the provincial and municipal governments and agencies because the 
texts that they contained were informative and written in a relatively clear, neutral style with reasonably short sentences. This style of text proved quite amenable to being processed by an MT system. Many words in the texts were already in the system dictionaries, and additional terms could easily be added. Specific issues cited by OLMC members who responded to the initial survey included disaster planning, justice and business (for the Fransaskois community), and health, social services and business (for the West Quebec community). Accordingly, six texts ${ }^{8}$ (three in English and three in French, and each approximately 325 words in length ${ }^{9}$ ) were selected as the basis for the surveys. All the texts were taken from relevant municipal or provincial government Web sites.

Of the three MT systems, Reverso Pro produced the highest quality results ${ }^{10}$ during the preliminary testing phase in each language, and so this system was retained for use during the next phase, where for each of the six texts, four translations were produced:

- A raw or unrevised machine translation (MT);

- A rapidly post-edited (RPE) machine translation (i.e., a translation where content errors were corrected, but stylistic changes were not made) ${ }^{11}$;

- A maximally post-edited (MPE) machine translation (i.e., a translation where both content and style were corrected to produce a text that resembles as closely as possible a human translation);

- $\quad$ A human translation (HT).

The time and cost for producing each of the four versions was also calculated, because whenever a text needs to be translated, the competing parameters of quality, time, and cost must always be considered. The methods used for determining the time and cost are described in the following paragraphs, and the actual time and cost required to produce each version are summarized in Tables 1 and 2 for the Fransaskois and the West Quebec OLMCs, respectively.

The raw machine-translations were produced by running the texts through the Reverso Pro MT system. Tests revealed that the time required to produce the raw output for each text was approximately two minutes, which included opening the software, importing the source text, and running it through the translation engine. Since each text was relatively short (approximately 325 words), in practical terms there was no difference in the processing time required to produce each of the raw machine-translations. Of course, an initial investment of time would be required in order to install the MT system and to learn how to use it, but this was not factored into the equation since it would be a once-off investment of time, and since even use of conventional translation resources, such as dictionaries or term banks, require investment of time for learning their proper use.

Four professional translators were hired to help produce the remaining target texts. Two of these translators worked from English to French to 
produce texts for the Fransaskois OLMC, and the others worked from French to English to produce texts for the West Quebec OLMC. Clearly it is not possible for different translators to have precisely the same ability, but every effort was made to find translators with comparable backgrounds and levels of experience. For each language direction, one translator produced the human translations, and the other did the post-editing (both RPE and MPE) of the raw MT output ${ }^{12}$. All translators were instructed to keep careful track of the time needed to complete their tasks.

In the case of post-editing, the post-editors began by taking the raw MT output and conducting the RPE. Once the RPE was complete, the posteditors saved a copy of the RPE text and recorded the amount of time that had been required for this task. Next, with the clock still running, the posteditors revisited the RPE text and gave it a more thorough revision to produce an MPE text, and recorded the total amount of editing time required. The editing time varied from text to text depending on the number and types of problems the MT system encountered in each text. Then, for both the RPE and MPE texts, the time required to produce the raw MT output (i.e. two minutes) was added to the time required for editing. This yielded the total time required to produce the two types of post-edited target text.

The cost of producing each version was also calculated. For the raw MT output, the price was set at $\$ 1.68^{13}$, on the basis that it took less than two minutes to launch the program, import the text and generate a raw translation. Obviously, this cost does not include the software's purchase price or time spent building dictionaries. However, we felt justified in excluding these costs for the following reasons. As noted previously, the texts used in this experiment required relatively few entries to be added. In any case, although dictionary-building is not strictly a once-off investment of time, it is an activity that will lessen considerably over time as the dictionaries grow larger and fewer entries need be added. Therefore, the amount of time spent on dictionary building in an early stage of an experiment such as ours would not be representative of the typical amount of time required to use the system on a long-term basis.

For the other versions, the cost was calculated using the average hourly rates charged by translators $(\$ 53.73)$ and editors $(\$ 50.16)$ as reported in the "Sondage de 2004 sur la tarification et les salaires" published by the professional translators' association the Ordre des Traducteurs, Terminologues et Interprètes Agréés du Québec (OTTIAQ). Although we calculated the post-editing costs using the full rate normally charged by editors, we could potentially have used a lower rate, since evidence in the literature suggests that post-editors are not always paid the full rate. For example, Chesterman and Wagner (2002, p. 125) note that freelance translators contracted by the European Union institutions to post-edit output produced by the Systran MT system are paid "at a rate equivalent to about half the normal rate for freelance translation." Similarly, Vasconcellos and Bostad (1992, p. 67) report that freelance translators hired to post-edit the output of the ENGSPAN MT system used by the PAHO "were being paid 55 percent 
of the HT rate." Had we used lower rates to calculate the costs of postediting, then these texts, which had already proved less expensive to produce than HT, would have been even less expensive as compared to HT. However, for these experiments we decided to be conservative in calculating the costs and so opted to use the full rate charged by editors as reported in the OTTIAQ survey of rates (OTTIAQ, 2004). The production times and costs for each of the texts are summarized in Tables 1 and 2.

Table 1. Time and cost required to produce French versions of English source texts for members of the Fransaskois OLMC

\begin{tabular}{|l|c|c|c|}
\hline & Text 1 & Text 2 & Text 3 \\
\hline Time raw MT & $2 \mathrm{~min}$ & $2 \mathrm{~min}$ & $2 \mathrm{~min}$ \\
\hline Cost raw MT & $\$ 1.68$ & $\$ 1.68$ & $\$ 1.68$ \\
\hline Time RPE & $28 \mathrm{~min}$ & $18 \mathrm{~min}$ & $22 \mathrm{~min}$ \\
\hline Cost RPE & $\$ 23.52$ & $\$ 15.12$ & $\$ 18.48$ \\
\hline Time MPE & $69 \mathrm{~min}$ & $53 \mathrm{~min}$ & $82 \mathrm{~min}$ \\
\hline Cost MPE & $\$ 57.96$ & $\$ 44.52$ & $\$ 68.88$ \\
\hline Time HT & $107 \mathrm{~min}$ & $110 \mathrm{~min}$ & $111 \mathrm{~min}$ \\
\hline Cost HT & $\$ 96.30$ & $\$ 99.00$ & $\$ 99.90$ \\
\hline
\end{tabular}

Table 2. Time and cost required to produce English versions of French source texts for members of the West Quebec OLMC.

\begin{tabular}{|l|c|c|c|}
\hline & Text 1 & Text 2 & Text 3 \\
\hline Time raw MT & $2 \mathrm{~min}$ & $2 \mathrm{~min}$ & $2 \mathrm{~min}$ \\
\hline Cost raw MT & $\$ 1.68$ & $\$ 1.68$ & $\$ 1.68$ \\
\hline Time RPE & $23 \mathrm{~min}$ & $31 \mathrm{~min}$ & $27 \mathrm{~min}$ \\
\hline Cost RPE & $\$ 19.32$ & $\$ 26.04$ & $\$ 22.68$ \\
\hline Time MPE & $62 \mathrm{~min}$ & $79 \mathrm{~min}$ & $74 \mathrm{~min}$ \\
\hline Cost MPE & $\$ 52.08$ & $\$ 66.36$ & $\$ 62.16$ \\
\hline Time HT & $98 \mathrm{~min}$ & $112 \mathrm{~min}$ & $108 \mathrm{~min}$ \\
\hline Cost HT & $\$ 88.20$ & $\$ 100.80$ & $\$ 97.20$ \\
\hline
\end{tabular}

The data show that, not surprisingly, raw MT was always the fastest and cheapest method of producing a text, followed by RPE, then MPE, and finally HT. For the texts used in these two experiments, it is notable that those produced using MP (which aims to produce texts comparable in quality to HT) were between $30 \%$ and $55 \%$ cheaper than HT and were also produced in a much shorter timeframe. 


\subsection{Survey and findings}

Once the various translations had been generated, the next step was to consult members of each OLMC to try to identify the reasons why they wanted the texts to be made available in the other official language, and to determine which of the four translated versions presented to them (MT, RPE, MPE or HT) best met their needs. To this end, two parallel online surveys were developed and made available ${ }^{14}$ - one aimed at members of the Fransaskois OLMC; the other at members of the West Quebec OLMC.

Members of the Fransaskois OLMC were contacted and invited to participate in this survey via mass electronic mailing through groups such as the Assemblée communautaire fransaskoise (ACF), the Conseil culturel fransaskois, the Association canadienne-française de Regina, the Fédération des francophones de Saskatoon, the Association communautaire Fransaskoise de Moose Jaw, the Association des Parents Fransaskois, and the Institut français at the University of Regina. The recipients of this invitation were invited to redistribute it to other potentially interested parties. As a result of these efforts, a total of 104 respondents participated in the survey aimed at the Fransaskois OLMC.

Similarly, members of the West Quebec OLMC were contacted and invited to participate in this survey via mass electronic mailing through groups such as the Regional Association for West Quebecers (RAWQ), the Community Table, the Outaouais Health and Social Services Community Network for the English-speaking Population, the English Network Resources in Community Health (ENRICH), the English Language Arts Network (ELAN), and the Quebec Community Groups Network. This effort netted a total of 119 responses to the survey aimed at the West Quebec OLMC.

\subsubsection{General profile questions}

The survey was posted on the Web and participants were able to respond anonymously. Because the surveys specifically targeted adult members of the Fransaskois and West Quebec OLMCs, participants were first asked to confirm that they were indeed members of the respecitive OLMCs and that they were over the age of 18 .

They were also asked to provide their gender ( $\mathrm{M}$ or F), age bracket (18-25 years; 26-40 years; 41-60 years; 61 years and over) and whether they considered themselves "language professionals" (e.g. translators, interpreters, terminologists, revisers, writers, language teachers, etc.). Unfortunately, no data were collected regarding the respondents' educational profiles, although in hindsight this data would have been informative. 


\subsubsection{Reasons for wanting texts to be translated}

Survey participants were then invited to read the source texts and to indicate why they would like such texts made available in their own language. As stressed by Edwards (1992, p. 48), probing the underlying reason, rather than simply asking Yes/No-type questions, can provide valuable insight into an OLMC. The findings for each of the two OLMCs are presented in the following sections.

\subsubsection{Fransaskois}

Members of the Fransaskois OLMC were asked to specify one or more reasons why they would like the English texts used in this study to be translated into French. A list of possible reasons was provided in the survey, but participants were also able to suggest their own reasons. The responses received are summarized in Table 3 in order of frequency.

Table 3. Reasons given by members of the Fransaskois OLMC for wanting translations (note that respondents were allowed to select more than one reason). Based on a population size of 19,500 and a sample size of 104 respondents, the margin of error is $\pm 8 \%$ with a confidence level of $90 \%$.

\begin{tabular}{|l|c|}
\hline Reason for wanting translation & \# of responses \\
\hline Cultural preservation & $80(76.9 \%)$ \\
\hline Faster processing of information & $38(36.5 \%)$ \\
\hline Greater confidence in comprehension & $24(23.1 \%)$ \\
\hline Teaching material (e.g. for children, students) & $24(23.1 \%)$ \\
\hline $\begin{array}{l}\text { Improvement of 2 } \\
\text { tion in translation) }\end{array}$ & $12(11.5 \%)$ \\
\hline Do not fully understand original & $6(5.8 \%)$ \\
\hline Other: Equity - it should be my right & $8(7.7 \%)$ \\
\hline
\end{tabular}

Reviewing the data for the Fransaskois community, we see that the most common reason for wanting to have the texts translated into French was as a means of cultural preservation. In other words, a considerable number of the Fransaskois participants tended to view translation not as a necessary tool for the functional transfer of linguistic content but rather as a public acknowledgement of the presence of their language and culture, and as a measure of it strength. As Lesage et al. (2008, p. 15) observe,

The ability of official language minorities to identify with their culture is enhanced when that culture comes out of the shadows of private life and assumes a public face. Only then are citizens able to feel a sense of belonging to something greater than themselves - a collective history, a common endeavour, an ambitious future. 
Bernard Lord (2008, p. 21), in reporting the results of his cross-Canada consultations with members of OLMCs, also underscores the value of culture for these communities, noting "the importance of culture is undeniable, not only for community vitality but also as a source of economic development and a way of fostering openness toward others." Accordingly, Lord (2008, p. 12) recommends that culture be given special attention in the new strategy for the next phase of the federal government's Action Plan for Official Languages ${ }^{15}$ Similarly, François Paré (1997, p. 14) notes that "Whatever its colonial, minority or insular context, the development and prestige of a culture are connected to the survival and the strategic importance of its language in the global linguistic economy." Paré's observation focuses in particular on literary works, but the general principle can be extended to the situation encountered in this experiment. In this case, members of the Fransaskois community viewed the translation of material on provincial and municipal government Web sites as a means of preserving and promoting their culture not so much because of the content of these sites per se, but rather because having greater amounts of material available in French will help to increase the visibility and vitality of their community, which in turn will help to revitalize linguistic duality. Indeed, this is supported by Churchill's observation (1998, p. 13) that the motivating force in seeking policies for official languages has been the "search for status and recognition of identity by different communities and constituencies of citizens."

Other reasons were provided that dealt more specifically with translation as a tool for linguistic transfer; however, these reasons were selected less frequently than the view that translation has an important role to play in the linguistic and cultural preservation of the Fransaskois community. These other reasons included the fact that some people felt that although they could understand English they processed information more quickly and easily in their native language, and had greater confidence that they had understood all the details of the text. Some respondents said that they would like to have more French-language texts available to use as teaching material, either to teach their own children or to use in more formal classroom settings. This may be explained in part by the fact that a relatively high proportion (48\%) of the respondents identified themselves as members of the language profession, which includes language teachers. A few others said they were trying to improve their own English-language skills and would appreciate having a French translation available so that they could verify if they had fully understood the English text. Only a very small number of people claimed not to have been able to understand the English texts sufficiently, and the remaining participants stated that they simply felt that, as Canadians, it should be their right to have this information available in French regardless of how well they could understand the English text. 


\subsubsection{West Quebecers}

In regard to the survey of the West Quebec OLMC, participants were asked to provide one or more reasons why they would like to have the Englishlanguage texts used in this study translated into French. A list of possible reasons was again provided in the survey, but participants could also suggest their own reasons. The responses received are summarized in Table 4 in order of frequency.

Table 4. Reasons given by members of the West Quebec OLMC for wanting translations (note that respondents were allowed to select more than one reason). Based on a population size of 35,580 and a sample size of 119 respondents, the margin of error is $\pm 8 \%$ with a confidence level of $90 \%$.

\begin{tabular}{|l|c|}
\hline Reason for wanting translation & \# of responses \\
\hline Greater confidence in comprehension & $72(60.5 \%)$ \\
\hline Faster processing of information & $60(50.4 \%)$ \\
\hline Do not fully understand original & $34(28.6 \%)$ \\
\hline $\begin{array}{l}\text { Improvement of } 2^{\text {nd }} \text { language skills (verifying informa- } \\
\text { tion in translation) }\end{array}$ & $22(18.5 \%)$ \\
\hline Cultural preservation & $13(10.9 \%)$ \\
\hline Teaching material (e.g. for children, students) & $0(0 \%)$ \\
\hline Other: & N/A \\
\hline
\end{tabular}

In contrast to the Fransaskois respondents, far more respondents from West Quebec (28.6\%) claimed not to be able to understand the source language text and therefore to need the translation in order to access the content. In addition, $60.5 \%$ felt they would be more confident that they had understood the text if they could read it in English, while 50.4\% believed that they would be able to process the information more quickly. Moreover, another $18.5 \%$ would have appreciated the opportunity to verify their understanding of the French-language text by being able to refer to the English translation. These findings seem to be supported by research carried out by Bishop (1999), who undertook a human resources development needs assessment for the English-speaking minority in the region of West Quebec.

As Bishop (1999, p. 23) reports, there appears to be a lack of confidence among English speakers in West Quebec regarding their ability to function in French. In discussing the results of a survey about employment opportunities for English-speakers in the Outaouais region, Bishop (1999, p. 28) explains in more detail that

Another contributing factor to unemployment in the Englishspeaking community in the Outaouais may be an existing perception among Anglophones that the level of French they possess is not sufficient enough to warrant even the search for employment. Respondents indicated that the prevailing political situation in the province 
has caused them to lose confidence in their abilities to function bilingually. Even if a person has a high level of French, he may not perceive himself to be sufficiently proficient in his second language to apply for positions requiring French language skills. (Bishop, 1999, p. 28)

Bishop's findings are supported by Lord (2008, p. 16), who notes that Anglophones in Quebec have difficulty finding employment because their level of bilingualism is considered imperfect; however, many of those who leave the province subsequently find bilingual jobs elsewhere, where their knowledge of French is considered above average. Although Bishop (1999) and Lord (2008) are discussing employment opportunities in particular, it is quite likely that the lack of confidence that West Quebecers have developed about their abilities to function in French spills into other aspects of their lives, such as their self-perceived ability to read and understand Frenchlanguage provincial and muncipal Web sites.

In addition, it is notable that among those West Quebec OLMC members who responded to the survey, 59\% were in the age bracket for 41 60 years, and $16 \%$ were in the 61 -and-over age bracket. As noted by the National Human Resources Development Committee for the English Language Minority (HRDCELM, 2000, p. 11) and by the Quebec Community Groups Network (QCGN, 2004, p. 5), shifting demographics, such as those in reaction to Bill 101 (discussed above), have resulted in disproportionately fewer youth and more seniors in English-speaking Quebec. Churchill (1998, p. 57) observes that an increasing number of English-speaking parents are beginning to enrol their children in French-immersion programs ${ }^{16}$, but notes that this is a relatively recent trend. The majority of Englishspeaking Quebecers over the age of 40 are thus less likely to have learned French intensively from an early age or to consider themselves bilingual.

In regard to other reasons, no respondent felt it was necessary to translate the texts to use them as teaching material. This is doubtlessly because vast amounts of original English-language material can be obtained relatively easily from other sources (e.g. the Internet, the nearby and predominantly anglophone province of Ontario). Relatively few of the respondents $(9.2 \%)$ identified themselves as members of the language profession, which includes language teachers.

Furthermore, a comparatively small percentage of West Quebecers $(10.9 \%)$ identified cultural preservation as a reason that motivated their desire to have the texts translated. This may be because West Quebecers, although not wishing to relinquish their right to use English as the official language of their choice, seem to acknowledge that their situation is somewhat different than that of their counterpart francophone OLMCs. As the Quebec Community Groups Network (QCGN, 2004, p. 5) notes, Englishspeakers in Quebec are beginning to more readily acknowledge that the global (rather than local) influence of English is a threat to Quebec. Moreover, as discussed previously, there appears to be growing consensus 
among English-speakers that French has a pre-eminent place in all aspects of life in Quebec and that bilingualism is becoming increasingly important for English-speakers.

\subsubsection{Preferred type of translation}

In the next step, participants were asked to read the four translated versions of a text. Then they were asked to choose, taking into account the quality of the translations and the time and cost required to produce them, which version they felt would best meet their needs. The results of the responses from members of the two OLMCs are presented in the following sections.

\subsubsection{Fransaskois}

Members of the Fransaskois OLMC were asked to indicate, keeping in mind the associated production time and cost, which translated version of a text (a raw machine-translated text, a rapidly post-edited machine-translated text, a maximally post-edited machine-translated text or a human translation) would best meet their needs,. The responses are summarized in Table 5.

Table 5. Preferences for type of translation among the Fransaskois OLMC. Based on a population size of 19,500 and a sample size of 104 respondents, the margin of error is $\pm 8 \%$ with a confidence level of $90 \%$.

\begin{tabular}{|l|c|}
\hline Type of translation & $\begin{array}{l}\text { \# of respondents selecting } \\
\text { this option }\end{array}$ \\
\hline Human translation (HT) & $74(71.1 \%)$ \\
\hline Maximal post-editing (MPE) & $22(21.2 \%)$ \\
\hline Rapid post-editing (RPE) & $8(7.7 \%)$ \\
\hline Raw machine translation (MT) & 0 \\
\hline Total & $104(100 \%)$ \\
\hline
\end{tabular}

On the basis of this survey, it is clear that unrevised MT output is unacceptable to members of the Fransaskois OLMC. None of the respondents selected the option, many of them took time to voice their dissatisfaction with the quality of the raw MT output in the comments section of the survey. Such comments included the following:

- “Je ne vois sincèrement pas l'utilité de traduire un texte de façon automatique sans révision. À ce moment, aussi bien le lire en anglais."

- "On peut remarquer que la traduction automatique a une couleur de mot à mot." 
- "Les traductions automatiques sans révision sont absolument à éviter si l'on veut que les francophones en milieu minoritaire améliorent leurs connaissances du français écrit."

At first glance, it seems that a significant majority of Fransaskois community members $(71.1 \%)$ do not appear willing to accept any form of MT output, even if it has been post-edited, feeling that only HT can fully meet their needs. However, a closer look at the data reveals interesting information.

As noted earlier, respondents were asked to indicate if they were language professionals. In the case of the Fransaskois OLMC, of the 104 respondents, $50(48 \%)$ consider themselves language professionals, and the remaining $54(52 \%)$ are Francophones who do not work in the language industry. If, as illustrated in Table 6 , the data are broken down according to these categories, then a somewhat different picture is revealed.

Table 6. Translation preferences of language professionals vs non-language professionals in the Fransaskois OLMC. ${ }^{17}$

\begin{tabular}{|l|c|c|}
\hline $\begin{array}{l}\text { Type of transla- } \\
\text { tion }\end{array}$ & $\begin{array}{c}\text { \# of language profession- } \\
\text { als selecting this option }\end{array}$ & $\begin{array}{c}\text { \# of non-language profes- } \\
\text { sionals selecting this op- } \\
\text { tion }\end{array}$ \\
\hline HT & $44(88 \%)$ & $30(55.6 \%)$ \\
\hline MPE & $6(12 \%)$ & $16(29.6 \%)$ \\
\hline RPE & 0 & $8(14.8 \%)$ \\
\hline Raw MT & 0 & 0 \\
\hline Total & $50(100 \%)$ & $54(100 \%)$ \\
\hline
\end{tabular}

In the survey, language professionals, who clearly have extremely high standards and expectations for language production, insist $88 \%$ of the time that HT is the only acceptable means of producing a target text. In contrast, members of the Fransaskois OLMC who do not work in the language industry are willing to accept some form of post-edited MT close to half the time. That nearly half the respondents to the survey are language professionals could be skewing the results since it is unlikely that half the members of the overall Fransaskois community work in the language industry. However, no reliable information about the actual number of Fransaskois working as language professionals could be found.

Detailed analysis of correlations has not been carried out, and so definitive conclusions cannot be drawn based on the data reported in this recipient evaluation. Nevertheless, it is possible to speculate that language professionals may harbour prejudices against MT for a number of reasons. As Hutchins (2001) and Yuste Rodrigo (2001) report, some translators seem to feel threatened by MT, fearing that it may cost them their livelihoods. Church and Hovy (1993, p. 249) report that others fear MT will contribute to reduced job satisfaction, noting that many translators do not 
wish to become post-editors, a task they perceive as tedious and dreary. Moreover, translators may fear that use of MT will result in production of lower-quality texts, thus hurting the general reputation of their profession. As Gerber (2008) explains;

Translators also tend to judge MT very harshly. This is often seen as self-preservation, and there is certainly an element of that. But professional translators are trained to adhere to a very high standard of accuracy. And professional ethics prevent them from accepting any translation job that they cannot deliver at the highest levels of quality. Is it any wonder that they find MT offensive? (Gerber, 2008, p. 16)

The survey findings appear to provide some broad support for Hutchins's (2001) observation that the general population may be more willing than language professionals to accept MT. According to Hutchins (2001, p. 8), "While poor quality output is not acceptable to translators, it is acceptable to most of the rest of the population, if they want immediate information, and the on-line 'culture' demands rapid access to and processing of information." This observation that the intended recipient of a text may have different needs, and therefore different standards, than a language professional has been confirmed in various instances.

For example, in describing customers who work in the business field, where "time is money," Allied Business Intelligence (ABI, 2002) reports that

Often, an MT program can generate the gist of an email or other message and allow a rapid reply with a reasonable degree of accuracy. This has become more acceptable in business, where the tolerance for low-quality texts has risen [...] and users are more willing to concede some quality to achieve expediency in communication. (ABI, 2002: 5.3)

In another example, experiments using MT in intelligence agencies and in the military produced similar observations. Holland et al. (2000, p. 246) note that agents who work as language professionals in intelligence agencies have relatively high degrees of translation training and considerable translation experience. In general these agents are much less tolerant of MT than are soldier-linguists in the military, who have considerably less formal training and experience in translation. In fact, when compared to intelligence agents, it has been observed that "soldiers seem disproportionately welcoming of automatic translation" (Hernandez et al., 2004, p. 95) and that "they [soldiers] are tolerant of lower quality translations" (Holland et al., 2000, p. 246).

Similarly, Gerber (2008, p. 16) reports a project at Intel Corporation that seeks to provide fully automated translation of technical knowledge base articles from English into Spanish in order to provide self-serve sup- 
port. The results have been relatively impressive: Adoption of EnglishSpanish MT for certain technical support articles has succeeded in deflecting support calls, and the quality is high enough that some human translation efforts have discontinued. As Gerber explains,

Sometimes the end user's standard isn't "the highest level of quality". In the case in point, Intel's standard was the ability to deflect support calls for a language that had very little technical support content before the project began. When the company was evaluating machine translation output to assess feasibility of an MT solution, human linguists rated the MT generally inadequate. But the company's representatives in central and South America evaluated the MT output as quite adequate for the purpose at hand - to provide better support to a Spanish-speaking audience and reduce the number of calls that resulted from the lack of Spanish-language self-help content. When the system was deployed, user responses to the question "did this information help answer your question" actually exceeded the satisfaction levels projected even by the regional representatives. (Gerber, 2008, p. 16)

Returning to our own experiment, the following comments were made by survey respondents who were language professionals. These comments display significant intolerance towards MT and clear preference for HT.

- “À mon avis la seule solution est de traduire tout texte par un traducteur humain, ou ne pas traduire du tout."

- $\quad$ "Aller vers un système de traduction automatique met notre langue à risque dans des contextes de vie où les 2 langues officielles se côtoient et crée pour celle-ci des interférences et nous en perdons parfois les mots justes."

- "Moi je préfère la traduction faite par un traducteur."

- “Les 'systèmes de traduction automatique' sont des monstres qui défigurent la langue française."

\subsubsection{West Quebecers}

Let us now turn our attention to the results gathered from the survey conducted in the West Quebec OLMC, summarized in Table 7. Participants were asked to indicate which translated version of a text (a raw machinetranslated text, a rapidly post-edited machine-translated text, a maximally post-edited machine-translated text or a human translation) would best meet their needs, keeping in mind the associated production time and cost. 
Table 7. Preferences for type of translation among the West Quebec OLMC members. Based on a population size of 35,580 and a sample size of 119 respondents, the margin of error is $\pm 8 \%$ with a confidence level of $90 \%$.

\begin{tabular}{|l|c|}
\hline Type of translation & $\begin{array}{l}\text { \# of respondents selecting } \\
\text { this option }\end{array}$ \\
\hline Human translation (HT) & $10(8.4 \%)$ \\
\hline Maximal post-editing (MPE) & $45(37.8 \%)$ \\
\hline Rapid post-editing (RPE) & $59(49.6 \%)$ \\
\hline Raw machine translation (MT) & $5(4.2 \%)$ \\
\hline Total & $119(100 \%)$ \\
\hline
\end{tabular}

Unlike the survey results of members of the Fransaskois OLMC, wherein no respondents felt that raw MT output could meet their needs, a small number $(4.2 \%)$ of West Quebecers felt that machine-translated texts represented a viable option. One might have expected this number to be higher because, as discussed above, a considerable number of respondents from West Quebec indicated that lack of ability and/or confidence in understanding the source text was a motivator for wanting it to be translated. In such circumstances, one might assume that MT could do a sufficiently good job of helping readers to understand the gist of the text. However, in this experiment the respondents were asked to choose which text among the four versions best met their needs, taking into account the time and money required to produce it. Presumably, therefore, they found the edited texts easier to read and process than the raw MT output. It would have been highly interesting to conduct a similar experiment in which the choice was simply between raw MT output and no translation (as was the case in the San Francisco experiment described by De Palma (2007)). In such circumstances, it is possible that more respondents might have been willing to accept raw MT output rather than nothing.

At the other extreme, however, it is revealing that fewer than $10 \%$ of the West Quebec respondents felt that HT offered the best value for money. This contrasts starkly to the responses of Fransaskois respondents, of whom a clear majority felt that only HT could truly meet their needs. In the survey of the West Quebec OLMC, only 9.2\% of the respondents identified themselves as being language professionals (as compared to $48 \%$ of the Fransaskois respondents), and among the language professionals, all opted for either HT or MPE. Again, no formal correlation analysis was carried out as part of this research, and it would have been complex to do so given the different sample sizes of self-reported language professionals in the two OLMCs. Nonetheless, we can speculate that the relatively low number of West Quebecers insisting on HT may be related to the fact that, as Hutchins (2001) and Gerber (2008) observe previously, the standards of the average intended recipient of these texts are likely to be less exacting than the standards of a language professional. In the case of the West Quebecers, more than $85 \%$ of the respondents were willing to entertain some form of post- 
edited MT output, and among these, nearly 50\% were content with MT output that had been rapidly post-edited rather than maximally post-edited. Again, if we consider the observations of Bishop (1999) and Lord (2008) regarding the fact that many West Quebecers are in fact quite bilingual but simply lack confidence in their ability to function in French, then it seems reasonable that a rapidly post-edited text could suffice as a sort of crutch that would allow those respondents to feel more confident that they had indeed understood the text.

It is also worth considering that, as noted previously, almost onethird of the English-speakers in the West Quebec OLMC are not native speakers of English and, as such, it is possible that they may have higher tolerance for lower-quality English than do native speakers. Unfortunately, survey respondents were not asked to indicate whether they were native speakers of English, so it is not possible to confirm this hypothesis using data generated from this experiment.

Another interesting observation about the respondents from West Quebec is that those who identified themselves as belonging to the older age brackets (i.e. 41-60 years and 61 years and older) were more likely to opt for either MPE or HT, while the vast majority of respondents who selected RPE or raw MT were under the age of 40. This would seem in-line with Churchill's (1998) observations that among the English-speaking residents of Quebec, the younger generations are typically more comfortable with the French language. The younger respondents may have been better equipped to process an English-language text that retains traces of French syntax or style, such as text translated by an MT system and only rapidly post-edited.

\section{Concluding remarks}

The recipient evaluation of MT output in two different OLMCs in Canada revealed a number of interesting points and seems to support several earlier observations made by other researchers.

Among the first things to note is that MT cannot simply be adopted wholesale as a solution for meeting the needs of Canada's OLMCs. Although some recipients are simply seeking functional translation, there are many other factors to be considered in a context of official legislation of the use of two languages.. These include factors that are quite sensitive (e.g. politics, citizens' rights, historical developments and the strength of a given language in a global context) and which therefore must be addressed carefully. Tt is critical to keep in mind a fact observed by other researchers, including Church and Hovy (1993), Lewis (1997), and Miller et al. (2001): The acceptability of MT output is not absolute but varies according to the purpose for which the text will be used. In our experiment, the two OLMCs had quite different overall reactions to the possibility of using some form of 
MT output to meet their translation needs. In examining these reactions, we can observe possible connections between the reasons why the translation is desired and the level of acceptance of MT output.

As Vasconcellos and Bostad (1992, p. 69), O'Hagan and Ashworth (2002, p. 9) and Wagner et al. (2002, p. 90) point out, MT seems most useful when the recipients simply want a general understanding of a text (i.e. personal assimilation of information). Our data support these observations and reveal that there was greater willingness to accept raw or rapidly postedited MT output when the respondents wanted translations primarily to be able to understand a text, process information more quickly and with greater confidence, or to improve their own knowledge of the source language, all of which can be considered forms of information assimilation. A general willingness to accept some form of MT output, and most often a relatively cheap and quick RPE text, was best exemplified by the West Quebec OLMC, in which the majority of participants were seeking functional translations that could help them to understand a text quickly and confidently.

In contrast, respondents who view translation as a means of preserving or promoting a culture, of providing equity for the two official languages, and of furnishing material that could be used to teach a language (all of which are forms of information dissemination rather than assimilation) are more likely to insist on the need for high-quality texts, even if it comes with a higher price tag and slower turnaround time. In this experiment, this type of need was expressed by most surveyed members of the Fransaskois OLMC, and the majority opted for HT or MPE. ${ }^{18}$

It is interesting, however, that the main group calling for HT rather than some form of post-edited MT output were language professionals. This would seem to provide additional confirmation that typical or "average" recipients are more open to the idea of MT than are language professionals. Even in the Fransaskois OLMC, where the main reasons for seeking translation were for dissemination rather than for information assimilation, almost half the respondents who were not members of the language industry felt that post-edited MT output could be a viable means of meeting their translation needs. Among the respondents receptive to considering some form of MT-based solution, two-thirds felt that the higher-quality MPE (rather than RPE) would be the most appropriate option.

Overall, the results of this recipient evaluation seem to indicate that, in the case of Canada's OLMCs, machine translation is a valid option that is worth exploring as a more cost-effective means of offering a greater range of translated materials to members of these communities. However, the needs in all OLMCs are not exactly the same across the country, so different forms of MT-based solutions would need to be developed for different OLMCs. Based on this research, it would seem that raw or rapidly postedited MT output could be effectively used in English-speaking OLMCs ${ }^{19}$, where translation needs are mainly for personal assimilation of information. In the French-speaking OLMCs, where recipients tend to view translation 
chiefly as a means of helping to preserve and promote their culture, there is a need for higher quality texts such as those produced through maximal post-editing of MT output. In both cases, however, an MT-based solution would offer considerable cost savings over an HT solution, which should make it possible to increase the overall amount of material made available in both official languages at the provincial and municipal level.

This is an important finding because, in Canada the members of OLMCs are considered to have equality of status as citizens. Recognition of the rights of Canadian citizens should be a provincial and a municipal responsibility, as well as a federal responsibility. If members of one community (the numeric majority in a given province) agree to provide services and support for citizens of a numeric minority (of the other official language group), the majority's agreement to such services should not be seen as granting a 'privilege'. The majority are recognizing the rights of citizenship that are not limited to a given place of residence - rights which they themselves should expect to enjoy if they move to a province where they would be in the numeric minority. However, it is clear that the budget for providing such services is not unlimited, so a cost-effective means of doing so must be sought. The results of this recipient evaluation seem to indicate that carefully considered use of MT could play an important role in the development of a cost-effective solution for offering a wider range of translation services to meet certain needs of Canada's OLMCs.

\section{Acknowledgements}

Funding for this research was provided by two separate grants awarded by the Social Sciences and Humanities Research Council (SSHRC) of Canada. In addition, seed funding for a pilot project with the Fransaskois community was provided by the Centre canadien de recherche sur les francophonies en milieu minoritaire (CRFM) de l'Institut français at the University of Regina in Saskatchewan. Thanks are also due to Nicolle Sauvage and Brian Gibb, who acted as community contacts in the two OLMCs, and to the two anonymous reviewers, who provided constructive and insightful feedback.

\section{Bibliography}

Adam, D. (2000). A call for action: Cross-Canada consultations by the Commissioner of Official Languages. Ottawa, ON: Office of the Commissioner of Official Languages.

Adam, D. (2001). Annual report of the Office of the Commissioner of Official Languages (20002001). Ottawa, ON: Minister of Public Works and Government Services Canada. Retrieved from OCOL: http://www.ocol-clo.gc.ca/html/ar_ra_2000_01_e.php

Adam, D. (2005). Annual report of the Office of the Commissioner of Official Languages (20042005), Vols 1 and 2. Ottawa, ON: Minister of Public Works and Government Services Canada. Retrieved from OCOL: http://www.ocol-clo.gc.ca/docs/e/2004_05_e.pdf

Allen, J. (2003). Post-editing. In H. Somers (Ed.), Computers and translation: $\bar{A}$ translator's guide (pp. 297-317). Amsterdam/Philadelphia, PA: John Benjamins. 
Allied Business Intelligence (ABI) (2002). Language translation, localization and globalization: World market forecasts, industry drivers and eSolutions. Oyster Bay, NJ: Allied Business Intelligence, Inc.

Bishop, L. (1999). Human resources development needs assessment for the English-speaking minority of the Outaouais. Huntingdon, QC: Community Table of the National Human Resources Development Committee for the English Linguistic Minority.

Bowker, L. (2008). Official language minority communities, machine translation, and translator education: Reflections on the status quo and considerations for the future. TTR: Traduction, Terminologie, Rédaction, 21(2), 15-61.

Brace, C. (2000). Language automation at the European Commission. In R. Sprung (Ed.), Translating into success. Cutting-edge strategies for going. multilingual in a global age (pp. 219224). American Translators Association Scholarly Monograph Series. Volume XI. Amsterdam/Philadelphia, PA: John Benjamins..

Canadian Translation Industry Sectoral Committee (CTISC) (1999). Survey of the Canadian translation industry: Human resources and export development strategy. Retrieved January 23, 2009 from http://www.uottawa.ca/associations/csict/princi-e.htm

Chesterman, A. \& Wagner, E. (2002). Can theory help translators? A dialogue between the ivory Tower and the wordface, Manchester: St. Jerome Publishing.

Church, K.W. \& Hovy, E.H. (1993). Good applications for crummy machine translation. Machine Translation, 8, 239-258.

Churchill, S. (1998). Official languages in Canada: Changing the language landscape. Ottawa, ON: Department of Canadian Heritage.

City of County of San Francisco. Translation services Accessed May 27, 2008 from http://www.sfgov.org/ site/translated.asp?lp=en_zt

Clavet, A. (2002). French on the Internet: Key to the Canadian identity and the knowledge economy. Follow-up study by the Commissioner of Official Languages. Ottawa, ON: Minister of Public Works and Government Services Canada. Retrieved from OCOL: http://www.ocol-clo.gc.ca/docs/e/fr_Internet_id_can-2002_e.pdf

DePalma, D.A. (2007). Limited English proficiency not a bar to citizen access. MultiLingual, 18(4), $46-50$

Dillinger, M. \& Gerber, L (2009). Success with machine translation: Automating knowledge-base translation. ClientSide News Magazine, 9(1), 10-11.

Dorr, B.J., Jordan, P., \& Benoit, J. (1999). A survey of current paradigms in machine translation. In M. Zelkowitz (Ed.), Advances in computers (Vol. 49, pp. 1-64). London: Academic Press.

Edwards, J. (1992). Sociopolitical aspects of language maintenance and loss: Towards a typology of minority language situations. In W. Fase, K. Jaspaert \& S. Kroon (Eds.), Maintenance and loss of minority languages (pp. 37-54). Amsterdam/Philadelphia, PA: John Benjamins.

Gerber, L. (2008). Recipes for success with machine translation: Ingredients for productive and stable MT deployments. ClientSide News Magazine, 8(11), 15-17.

Guyon, A. (2003). Machine translation and the virtual museum of Canada (VMC). Retrieved August 30, 2009 from http://www.chin.gc.ca/English/Pdf/Digital_Content/Machine Translation/Machine_Translation.pdf

Henisz-Dostert, B., Ross Macdonald, R., \& Zarechnak, M. (1979). Machine translation. The Hague: Mouton Publishers.

Hernandez, L., Turner, J. \& Holland, M. (2004). Feedback from the field: The challenge of users in motion. In R Frederking \& K. Taylor (Eds.), Machine translation: From real users to Research (pp. 94-101). Berlin: Springer.

Holland, M., Schlesiger, C. \& Tate, C. (2000). Evaluating embedded machine translation in military field exercises. In J. White (Ed.), Envisioning machine translation in the information future (pp.239-247). Berlin: Springer.

Hutchins, J. (2001). Machine translation and human translation: In competition or in complementation? International Journal of Translation, 13(1-2), 5-20.

Jedwab, J. \& Maynard, H. (2008). Politics of community: The evolving challenge of representing English-speaking Quebecers. In R. Bourhis (Ed.), The vitality of the English-speaking communities of Quebec: From community decline to revival. Montreal, QC: CEETUM, Université de Montréal. Retrieved January 1, 2009 from http://www.ceetum.umontreal.ca/ pdf/Jedwab\&Maynard.pdf

Langlais, P., Leplus, T., Gandrabur, S. \& Lapalme, G. (2005). From the real world to real words: the METEO case. In Proceedings of the 10th European Association for Machine Translation Conference: Practical applications of machine translation; Budapest, Hungary, 
May 30-31, 2005. (pp. 166-175). Retrieved August 31, 2009 from http://www.mtarchive.info/EAMT-2005-Langlais.pdf

Lewis, T. (1997). Do you have a translation tool strategy? Language International, 9(5), 16-18.

L'Homme, M. (2008). Initiation à la traductique, $2^{e}$ édition. Brossard, QC: Linguatech.

Loffler-Laurian, A.(1996). La traduction automatique. Villeneuve d'Ascq: Presses Universitaires du Septentrion.

Lord, B. (2008). Report on the government of Canada's consultations on linguistic duality and official languages. Retrieved from Canadian Heritage web site: http://www.canadianheritage.gc.ca/pc-ch/consultations/lo-ol_2008/lord_e.pdf

Meta4 Creative Communications \& Micheline Lesage \& Associates (2008). Federal government support for the arts and culture in official language minority communities. Report prepared for the Office of the Commissioner of Official Languages. Retrieved from OCOL Web site: http://www.ocol-clo.gc.ca/docs/e/ arts_culture_e.pdf

Miller, K., Gates, D., Underwood, N., \& Magdalen J. (2001). Evaluation of machine translation output for an unknown source language: Report of an ISLE-based investigation. In Proceedings of the Machine Translation Summit VIII; Santiago de Compostela, Spain (September 18-22, 2001). Retrieved December 19, 2008 from: http://www.eamt.org/ summitVIII/papers/miller-2.pdf

National Human Resources Development Committee for the English Linguistic Minority (NHRDCLEM), (2000). Community economic development perspectives: Needs assessment report of the diverse English Linguistic minority communities across Quebec. Huntingdon, QC: Community Table of the National Human Resources Development Committee for the English Linguistic Minority.

Nuutila, P. (1996). Roughlate service for in-house customers. In Proceedings from the Aslib Conference: Translating and the Computer 18; London, UK, November 14-15, 1996).

Office of the Commissioner of Official Languages (OCOL), (1999). The Government of Canada and French on the Internet. Ottawa, ON: Minister of Public Works and Government Services Canada. Retrieved January 23, 2009 from OCOL Web site: http://www.ocolclo.gc.ca/html/gov_fr_internet_gouv_fran_e.php

Office of the Commissioner of Official Languages (OCOL), (2005). Bridging the digital divide: Official languages on the Internet. Ottawa, ON: Minister of Public Works and Government Services Canada. Retrieved January 27, 2009 from OCOL Web site: http://www.ocol-clo.gc.ca/html/stu_etu_092005_e.php

Office of the Commissioner of Official Languages (OCOL), (2007). French culture and learning French as a second language: Perceptions of the Saskatchewan public. Ottawa, ON: Minister of Public Works and Government Services Canada. Retrieved January 16, 2009 from OCOL Web site: http://www.ocol-clo.gc.ca/docs/e/perceptions_e.pdf

O'Hagan, M. \& Ashworth, D. (2002). Translation-mediated communication in a digital world. Clevedon: Multilingual Matters.

Ordre des Traducteurs, Terminologues et Interprètes Agréés du Québec (OTTIAQ), (2004). Sondage de 2004 sur la tarification et les salaires. Document distributed to OTTIAQ members.

Paré, F. (1997). Exiguity: Reflections on the margins of literature. L. Burman (Translated in English. French original Les littratures de l'exigut: Essai, 1993). Waterloo, ON: Wilfred Laurier University Press.

Pottie, K., Ng, E., Spitzer, D., Mohammed, A., \& Glazier, R. (2008). Language proficiency, gender and self-reported health: An analysis of the first two waves of the Longitudinal Survey of Immigrants to Canada. Canadian Journal of Public Health, 99(6), 505-510.

Quebec Community Groups Network (QCGN), (2004). Community development plan for the English-speaking communities of Quebec. Ottawa, ON: Department of Canadian Heritage. Retrieved January 19, 2008 from http://www.westquebecers.com/Community_Outreach/ QCGN/aCommunity_Development_Plan_published_version.pdf

Senez, D. (1998). Post-editing service for machine translation users at the European Commission. In Proceedings from the Aslib Conference: Translating and the Computer 20; London, November 12-13 1998.

Shadbolt, D. (2002). The translation industry in Canada. Multilingual Computing and Technology, 13(2), 30-34.

Somers, H. (2003). Translation technologies and minority languages. In H. Somers (Ed.), Computers and translation: A translator's guide (pp. 87-103) Amsterdam/Philadelphia, PA: John Benjamins. 
Standing Joint Committee On Official Languages (SJCOL), (2002). The Official Language Minority Communities Told Us... Ottawa, ON: Minister of Public Works and Government Services Canada. Retrieved January 23, 2009 from: http://cmte.parl.gc.ca/cmte/ CommitteePublication.aspx?COM=223\&Lang=1\&SourceId=37139

Statistics Canada. 2006 Retrieved January 25, 2009 from: http://www12.statcan.ca/english/ Search/secondary_search_index.cfm

Thouin, B. (1982). The METEO system. In V. Lawson (Ed.), Practical experience of machine translation (pp. 39-44). Amsterdam/New York, NY/Oxford: North-Holland Publishing Company. Retrieved August 31, 2009 from: http://www.mt-archive.info/Aslib-1981Thouin.pdf

Trujillo, A. (1999). Translation engines: Techniques for machine translation. London: Springer.

Vasconcellos, M. \& Bostad, D. (1992). Machine translation in a high-volume translation environment. In J. Newton (Ed.), Computers in translation: A practical appraisal (pp. 5877). London/New York, NY: Routledge.

Wagner, E., Bech, S. \& Martínez, J. (2002). Translating for the European Union institutions. Manchester: St. Jerome Publishing.

White, J. (2003). How to evaluate machine translation. In H. Somers (Ed.), Computers and translation: A translator's guide (pp. 211-244). Amsterdam/Philadelphia, PA: John Benjamins.

Yuste Rodrigo, E. (2001). Making MT commonplace in translation training curricula: Too many misconceptions, so much potential! In Proceedings of the Machine Translation Summit VIII; Santiago de Compostela, Spain, September 18-22, 2001. Retrieved January 6, 2009 from: http://www.dlsi.ua.es/tmt/docum/TMT7.pdf

\section{Appendix}

This appendix contains samples of the texts used as source texts for the experiments described in this paper.

\section{ENGLISH-LANGUAGE SOURCE TEXT: Staying Safe During Disasters}

Source: http://www.regina.ca/content/info_services/emergency_services/ during.shtml

\section{During a Tornado}

- If you are in a building go to the basement immediately. If there isn't one, crouch or lie flat under heavy furniture in an inner hallway or small inner room or stairwell away from windows. Stay away from large halls, arenas, shopping malls, and so on as their roofs could collapse.

- If you are outside and there is no shelter, lie down in a ditch or ravine, protecting your head.

- If you are driving, get out of and away from the car. It could blow through the air or roll over on you. Lie down as above.

\section{During a Severe Lighting Storm}

- If you are in a building, stay inside and away from windows, doors, fireplaces, radiators, stoves, metal pipes, sinks or other electrical charge conductors. Unplug TVs, radios, toasters and other electrical appliances. Do not use the phone or other electrical equipment.

- If you are outside, seek shelter in a building, cave or depressed area. If you are caught in the open, crouch down with your feet close together and your head down (in the "leap-frog" position). Don't lie flat - by minimizing your 
contact with the ground you reduce the risk of being electrocuted by a ground charge. Keep away from telephone and power lines, fences, trees and hilltops. Get off bicycles, motorcycles and tractors.

- If you are in a car, stop the car and stay in it. Do not stop near trees or power lines that could fall.

\section{During a Flood}

- Turn off basement furnaces and the outside gas valve. Shut off the electricity. If the area around the fuse box or circuit breaker is wet, stand on a dry board and shut off the power with a dry wooden stick.

- Never try to cross a flooded area on foot. The fast water could sweep you away.

- If you are in a car, try not to drive through floodwaters. Fast water could sweep your car away. However, if you are caught in fast rising waters and your car stalls, leave it and save yourself and your passengers.

\section{During a Winter Power Failure}

- Turn the thermostat(s) down to a minimum and turn off all appliances, electronic equipment and tools to prevent injury, damage to equipment and fire. Power can also be restored more easily when the system is not overloaded.

- Use proper candleholders. Never leave lit candles unattended.

Remember: Do not use charcoal or gas barbecues, camping heating equipment, or home generators indoors.

\section{FRENCH-LANGUAGE SOURCE TEXT: Notre santé et notre environnement en Outaouais}

Source: http://www.santepublique-outaouais.qc.ca/app/DocRepository/ 1.doc

Dans l'ensemble, nous pouvons dire que l'Outaouais est privilégiée au point de vue environnemental. L'air extérieur, l'eau de nos plans et cours d'eau ainsi que nos sols sont relativement peu pollués, si nous les comparons à d'autres régions du Québec et du monde.

\section{Quelques points saillants}

Entre 2002 et 2006, on a enregistré 58 jours de mauvaise qualité de l'air à Gatineau. Les véhicules constituent la principale source de pollution atmosphérique et produisent près de $50 \%$ des gaz à effet de serre. Aussi, la ville de Gatineau doit-elle davantage développer les transports en commun et inciter ses citoyens à réduire l'utilisation de leur véhicule.

L'air intérieur est un élément sur lequel les citoyens ont un contrôle encore plus grand. Comme nous passons $90 \%$ de notre temps à l'intérieur, il est important de s'assurer de la qualité de l'air intérieur que nous respirons. Chaque année, on dénombre une trentaine de cas d'intoxication au monoxyde de carbone (CO) 
en Outaouais. Environ $60 \%$ de ces intoxications se produisent dans les résidences, les autres surviennent au travail ou ailleurs. Outre le $\mathrm{CO}$, les éléments les plus menaçants à l'intérieur sont : les moisissures et les particules émises par certains matériaux de construction.

Un autre risque vient des émanations de radon dans le sous-sol de certaines maisons. Le radon est un produit de la désintégration naturelle de l'uranium. Certains endroits de notre territoire comme Chelsea, Cantley, le Pontiac et la Haute-Gatineau sont caractérisés par une concentration importante d'uranium. Par conséquent, les possibilités d'avoir de fortes concentrations de radon dans les sous-sols des maisons sont plus grandes dans ces endroits.

Dans ces mêmes secteurs de l'Outaouais, l'uranium peut aussi constituer un problème de santé dans l'eau des puits. Comme $27 \%$ de la population de l'Outaouais est approvisionnée en eau potable par des puits, il est important de sensibiliser les propriétaires de puits aux risques tels que les bactéries et les fortes concentrations de nitrates et d'uranium dans leur eau. Une étude réalisée en 2002 a permis d'identifier des taux élevés d'uranium dans l'eau de 11 puits sur 160 dans la Haute-Gatineau.

\footnotetext{
1 A notable exception is, of course, the well-known Météo machine translation system, which has long been used to translate weather forecasts issued by Environment Canada from English into French. For a historical overview of the development and application of the Météo system, see Thouin (1982), and for more recent discussion, see Langlais et al. (2005).

2 The exception is province of New Brunswick, whose provincial constitution mandates that it be an officially bilingual province.

3 The study of the Fransaskois OLMC was undertaken in 2006-2007 with the help of a one-year grant from the Social Sciences and Humanities Research Council (SSHRC) of Canada (8582005-0002). Preliminary results were reported in Bowker (2008).

4 The study of the West Quebec OLMC was undertaken in 2007-2008, one year after the study of the Fransaskois OLMC, with the the help of another one-year grant from the Social Sciences and Humanities Research Council (SSHRC) of Canada (858-2006-0008). The results of this study are being reported here for the first time.

5 MT systems have already been used to help translate a number of different documents for the federal government, including weather forecasts produced by Environment Canada (translated by the Météo MT system) and job advertisements for the JobBank operated by Service Canada (translated using the Reverso Pro MT system); however, these represent quite restricted sublanguages. MT systems have not yet been widely used by the Canadian government to translate texts containing less restricted language.

${ }^{6}$ We were not given direct access to the membership lists of these two associations, and so it is not possible to know exactly how many people received the invitiation to participate in this initial survey. Both associations claim, however, to have over 200 members each. In addition, as part of the information letter accompanying the survey, potential participants were invited to forward the invitation to other potentially interested parties.

${ }^{7}$ Commercial systems were selected because they typically offer better quality translation than the systems freely available on the Internet. However, given the emphasis placed on the need to ensure that official languages policies be kept to a reasonable cost, it is important to note that all the systems tested are available for a very moderate price (less than Cdn\$500) and all permit customization of the dictionaries in order to allow for improved output quality.

${ }^{8}$ Samples of some of the texts used in this research are found in the Appendix.
} 
${ }^{9}$ Ideally, it would have been preferable to use a greater number of texts and/or longer texts; however, we had to take into account that we were asking volunteers to read four versions of each text, and we did not want the overall task to become too onerous.

10 System quality was determined using subjective measures by taking the raw translations produced by each of the three MT systems and, for each text, asking three certified translators to rank the translated versions according to basic guidelines of accuracy and style. For four of the six texts, all the translators gave the highest ranking to the Reverso Pro output. For the remaining texts, two of the three translators ranked the Reverso Pro output as the highest quality, while the third translator ranked it as second. Note that the texts were labelled with a reference number only, and not the system name. In addition, the translators had access to the source text as a point of departure for determining the accuracy of the translated versions.

11 As Allen (2003, p. 302) explains, RPE is "strictly minimal editing on texts in order to remove blatant and significant errors and therefore stylistic issues should not be considered. The objective is to provide the minimum amount of necessary correction work that can be made on a text in order for the text to be fully understandable as a comprehensible element of information.

12 Note that in the case of post-editing, both translators had prior experience in this area.

13 Prices are given in Canadian dollars since these experiments took place in Canada.

${ }^{14}$ Surveys were conducted in accordance with the ethics policies of the Research Grants and Ethics Services (RGES) of the University of Ottawa (Ethics certificate number 09-05-06).

15 The original Action Plan for Official Languages (2003) was introduced to give new momentum to the federal policy on official bilingualism. Presented as a 5-year plan (2003-2008), its goal is to enhance and promote linguistic duality and to foster the development and vitality of OLMCs. It addresses issues relating to health services, immigration, education and literacy; however, it has been criticized for making no specific mention of culture. According to Lesage et al. (2008, p. 8), this omission was deeply disappointing to OLMC members and left them feeling vulnerable.

${ }^{16}$ French immersion programs are those where English-speaking students study most subjects of the school day through French as a medium of instruction.

17 Note that it was not possible to calculate a margin of error or confidence level for this data because no reliable information could be found about the population of language professionals in the Fransaskois OLMC as a whole.

${ }^{18}$ Note that in this experiment, recipients were conducting a comparative evaluation in which they were assessing the acceptability of different versions of a translated text. It would be interesting to conduct a slightly different survey, in which the respondents were limited to choosing between MT and no translation at all (i.e. to set up a situation similar to that described by DePalma (2007) for the city of San Francisco Web site mentioned in the introductory section of this paper). It would be of interest to see how this might affect the outcome. Based on the results of the present research, we might hypothesize that most members of the West Quebec OLMC would tend to favour MT given that their needs are mainly for information assimilation, whereas members of the Fransaskois OLMC would more likely opt for no translation since their needs are more oriented to information dissemination.

${ }^{19}$ Even here, we must be very careful about over-generalizing in regards to the needs of Englishspeaking OLMCs since it is quite likely that different English-speaking OLMCs have different needs. For example, the needs of a largely urban, English-speaking OLMC, such as that found in the Montreal region, are likely to be quite different than the needs of a more rural or isolated, English-speaking OLMC, such as the one located on the Magdalen Islands in the Gulf of St. Lawrence. This means that any MT-based solution must be tailored to the specific needs of the intended recipients. 